\title{
Malpractice claims and Canadian gastroenterology
}

\author{
PAUL C ADAMS, MD, FRCPC
}

PC ADAMS. Malpractice claims and Canadian gastroenterology. Can J Gastroenterol 1993;7(3):306-310. Data on medical malpractice claims specific to gastroenterology obtained from the Canadian Medical Protective Association from 1976 to 1989 were reviewed. There were 23 legal actions in which a significant degree of responsibility was assigned to the gastroenterologist. Of these 23 cases, there were nine cases of iatrogenic injury associated with endoscopy (gastroscopy three, colonoscopy three, endoscopic retrograde cholangiopancreatography two, laparoscopy one), lack of informed consent in two cases, diagnostic error in two cases, and one case of delayed recognition of complications, delayed referral and failure to follow-up the patient. Endoscopy-related legal incidents involving specialists not designated as gastroenterologists (surgeons, internists) were not included in this analysis. These findings are contrasted with 1096 gastroenterology related malpractice cases from the Physicians Insurer's Association of America. A risk management strategy is discussed in the context of an increasing trend in the number of medical malpractice claims in Canada.

Key Words: Endoscopy, Jurisprudence, Medicolegal, Negligence

\section{Procès en responsabilité médicale dans le domaine de la gastro-entérologie au Canada}

RÉSUMÉ: Les statistiques de poursuites judiciaires pour erreur médicale dans le domaine de la gastro-entérologie ont été obtenues de l'Association canadienne de protection médicale pour une période allant de 1976 à 1989. Vingt-trois poursuites ont été intentées dans le cadre desquelles un degré important de responsabilité a été imputé au gastro-entérologue. De ces 23 cas, neuf concernaient une lésion iatrogène associée à l'endoscopie (gastroscopie, trois; coloscopie, trois; cholangiopancréatographie rétrograde endoscopique, deux; laparoscopie, un), deux cas concernaient l'absence de consentement éclairé, deux concernaient une erreur diagnostique, et un concernait une identification trop tardive des complications, une consultation trop tardive et l'absence de suivi. Les litiges relatifs à l'endoscopie impliquant des spécialistes qui n'étaient pas gastro-entérologues (chirurgiens, internistes) n'ont pas été inclus dans cette analyse. Ces résultats sont comparés aux 1096 poursuites pour responsabilité médicale en gastro-entérologie cités par le Physicians Insurer's Association of America aux États-Unis. Une stratégie de gestion du risque est présentement à l'étude, étant donné que le nombre de poursuites en responsabilité médicale tend à augmenter au Canada.

Department of Medicine, University Hospital, University of Western Ontario, London, Ontario

Correspondence: Dr Paul C Adams, Department of Gastroenterology, University Hospital, PO Box 5339, 339 Windermere Road, London, Ontario N6A 5A5. Telephone (519) 663-3513, Fax (519) 663-3232

Received for publication June 3, 1992. Accepted November 25, 1992
$\mathrm{M}$ EDICAL MALPRACTICE HAS BEEN a predominant concern of physicians in the United States for the past 25 years. Despite legal measures in some states to control malpractice, the claim frequency and the number of dollars paid per claim grew at an alarming rate during the $1980 \mathrm{~s}(1,2)$. Because of major differences in legal systems, malpractice has been less common in Canada; however, the prevalence of malpractice claims has been rising. In order to establish a risk management strategy for the Canadian gastroenterologist, a study of the gastroenterology malpractice claims in Canada from 1976-89 was undertaken and compared with similar data available from American studies.

\section{MATERIALS AND METHODS}

The Canadian data were obtained with permission from the Canadian Medical Protective Association (CMPA) which is a mutual medical defence organization. Closed legal actions involving designated gastroenterologists in which the major responsibility for the legal action was attributed to the gastroenterologist were analyzed. This survey may not reflect the liability affecting all endo-scopists and gastroenterologists since many physicians providing this type of care are surgeons, internists and other types of physicians. There were many more cases in which a gastroenterologist was named in a legal action with a large number of other physicians; however, these were not included in the analysis because of the lack of available data from the CMPA. 


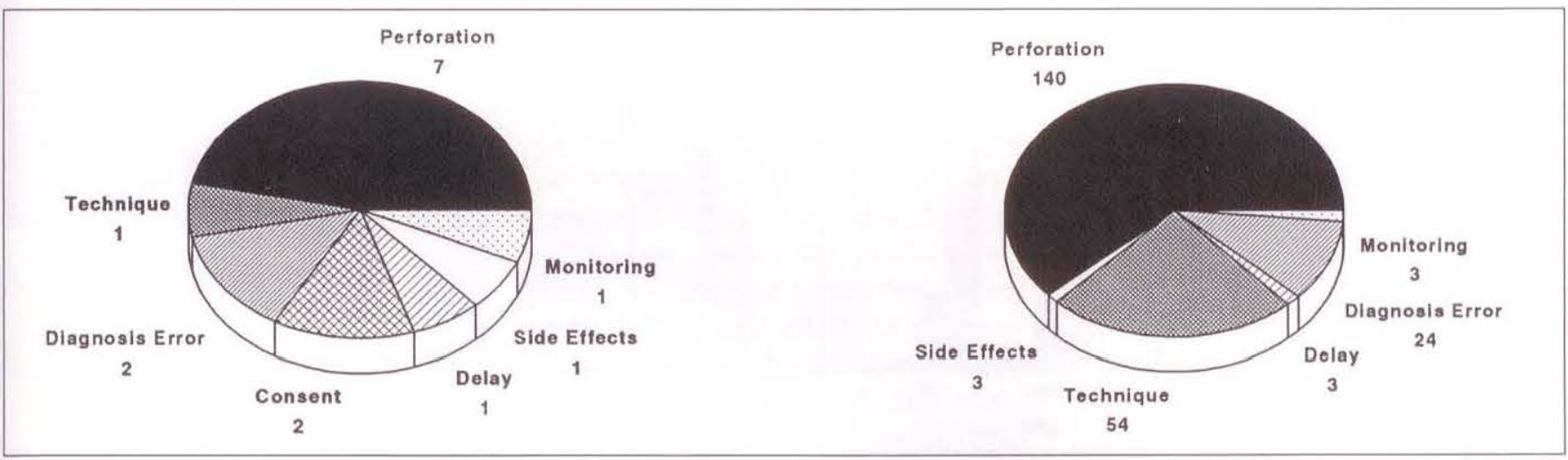

Figure 1) A comparison of the number of gastroenterology-related cases resulting in legal action and the general cause of the claim in (left) Canadian Medical Protection Association and (right) the Physicians Insurer's Association of America (3)

The American data were obtained from several sources but primarily from a data bank of the Physicians Insurer's Association of America (3). This is a business association of physicianowned liability insurance companies which insure over $50 \%$ of private practising physicians and surgeons in the United States. This database contains 68,740 claims and suits with indemnity payments greater than US\$2.1 billion.

\section{RESULTS}

Canadian data: There were 23 cases of gastroenterology-specific legal actions registered by the CMPA from 1976 to 1989. The gastroenterology-specific legal actions are classified into subgroups in Figure 1. Table 1 categorizes these 23 legal actions according to the specific procedure and compares similar data from the United States. The legal outcome of the 23 cases is summarized in Table 2.

The case which went to trial with a judgement against the physician involved a case of Crohn's disease in which steroid therapy resulted in avascular necrosis of the hip. The judge found that the dose of prednisone was excessive and that the diagnosis of Crohn's disease was not well estab. lished. The judge found that the patient had not been properly informed concerning the potential risks of systemic steroids and ruled that appropriate informed consent had not been obtained.

One case requiring settlement involved esophageal perforation at the time of gastroscopy which led to medi- astinitis, pericarditis and death. The perforation was not considered negligent but the delay in recognizing the complications of the esophageal perforation led to the settlement.

Another case involved a patient who had an endoscopic retrograde cholangiopancreatography (ERCP) as an extension of a gastroscopy when consent had only been obtained for gastroscopy. The complications associated with the ERCP were not considered negligent but the lack of informed consent led to this settlement.

Many cases are initiated that do not reach legal resolution. The number of legal actions commenced, actions settled and actions proceeding to trial handled by the CMPA for all categories of physicians from 1986-90 is shown in Figure 2. The medical malpractice insurance premiums of Canadian gastroenterologists from 1986-90 are shown in Figure 3. A comparison of the frequency of legal claims per 100 physicians in Canada and the United States is shown in Figure 4.

American data: Of 68,740 claims in the American database, 39,642 (68\%) have been closed without an indemnity payment and 15\% of the cases are still pending. Gerstenberger et al (3) identi-

\section{TABLE 1}

Classification of Canadian gastroenterology-specific legal claims

\begin{tabular}{lc}
\hline Category of legal action & Number \\
\hline Complication of gastroscopy & 4 \\
Complication of colonoscopy & 3 \\
Complication of ERCP & 4 \\
Complication of laparoscopy & 1 \\
Complications of steroid therapy & 3 \\
Incorrect diagnosis & 3 \\
Injection site problems & 2 \\
Medication error & 1 \\
Deferral of surgery because of medical illness & 1 \\
Travel advice with ulcerative colitis & 1 \\
\hline
\end{tabular}

ERCP Endoscopic retrograde cholangiopancreatography

TABLE 2

Legal outcome of 23 Canadian gastroenterology-specific malpractice claims

\begin{tabular}{lc}
\hline Legal outcome & Number \\
\hline Consent withdrawal (case withdrawn by the plaintiff) & 18 \\
Case to trial with judgement in favour of physician & 2 \\
Case to trial with judgement against physician & 1 \\
Case settled due to lack of expert support & 2
\end{tabular}




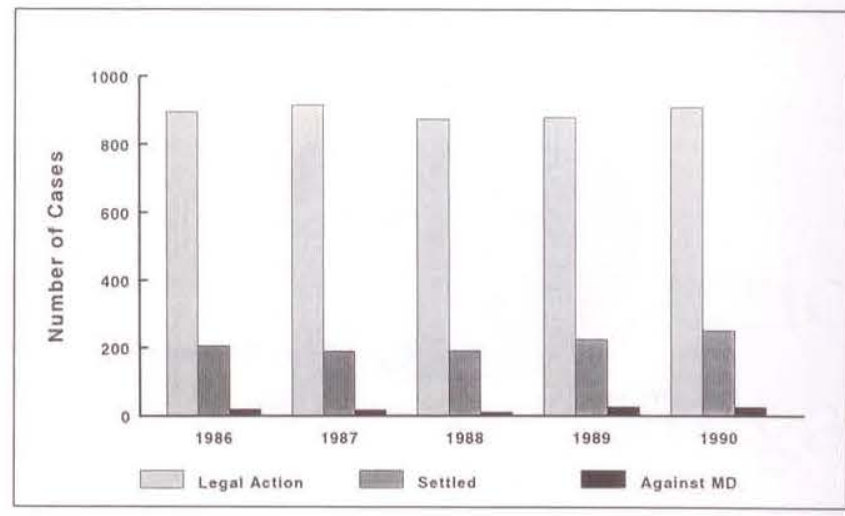

Figure 2) Total legal actions initiated, settled, and settled with the ruling against the physician (CMPA data 1986-90)

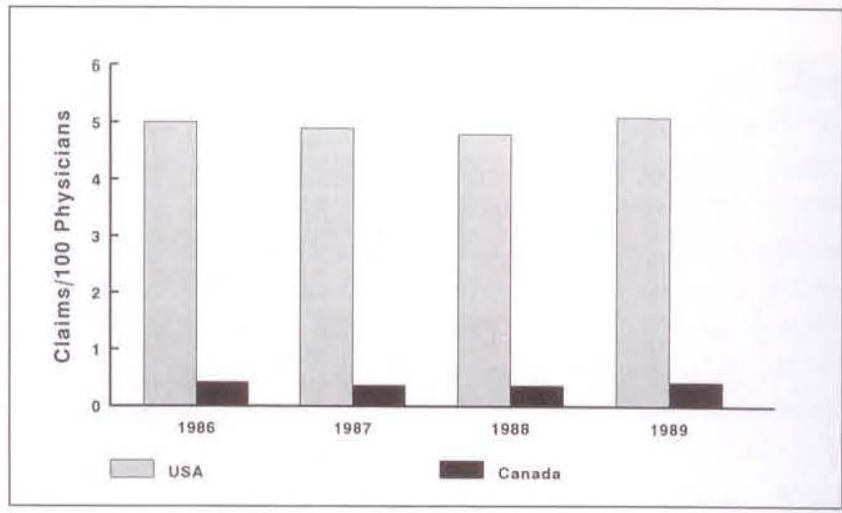

Figure 4) Comparison of the number of claims per 100 physicians in the United States and Canada

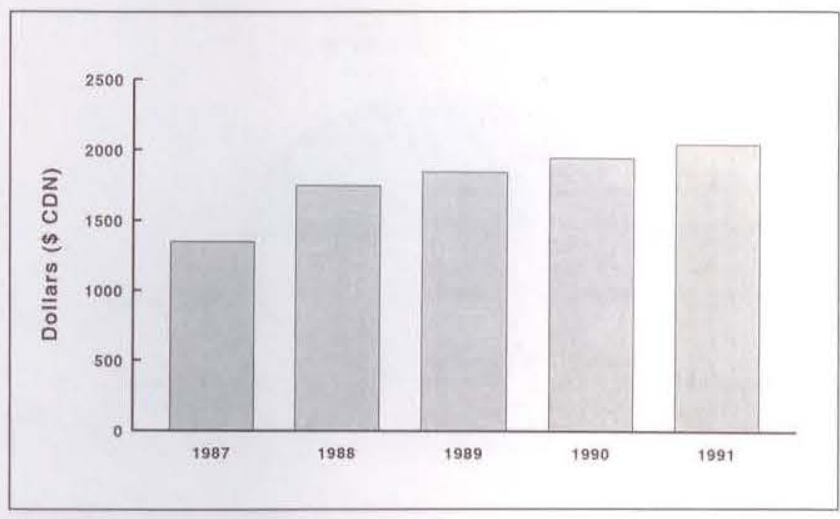

Figure 3) Annual malpractice premiums for Canadian gastroenterologists (CMPA data)

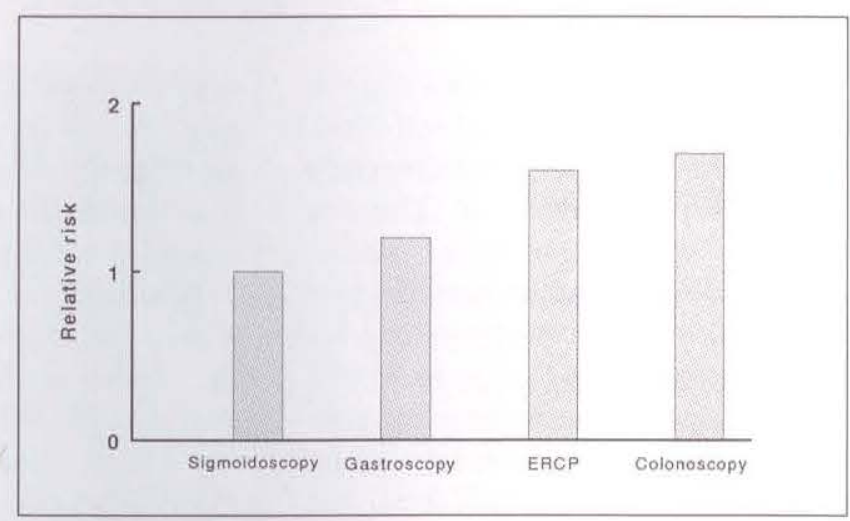

Figure 5) Relative risk of malpractice claims in the United States according to the endoscopic procedure fied 610 endoscopy-associated and 486 gastroenterology-associated claim files of the Physicians Insurer's Association of America. In the gastroenterologyspecific claims, 'improper performance' is cited in $55 \%$ of misadventures. The next most frequent category is diagnostic error, and most of these cases represent failure to diagnose colorectal carcinoma. Failure to diagnose a nongastrointestinal malignancy (gynecological and pulmonary) has also led to legal action against the gastroenterologist. Another observation was that the risk of a malpractice suit is relatively similar with all types of endoscopic procedures. Even though colonoscopy and ERCP are clearly higher risk than flexible sigmoidoscopy, the relative risks of malpractice differ only slightly (Figure 5).

\section{DISCUSSION}

The most striking observation from this survey was the marked difference in the number of malpractice claims between Canada and the United States (Figure 4). Contingency fees in the American legal system allow for any patient to seek financial compensation with minimal financial outlay. Furthermore, since litigation lawyers are usually compensated as a percentage of the award, the magnitude of the legal claims has grown considerably. The growing mistrust of physicians and the litigious nature of all aspects of American life are also factors that have contributed to the increase. Because of the considerable expense involved in cases proceeding to court, many private American insurance carriers would prefer cases against physicans to be settled quickly without going to court. The Canadian system, which is based on British common law, more often requires fee for service for medical malpractice suits. This system discourages the initiation of trivial legal claims but may provide an impediment to the financially disadvantaged patient that has been injured as a result of medical negligence. However, contingency fees have been used in Alberta and have been recommended in an internal report prepared for the Law Society of Upper Canada for the province of $\mathrm{On}$ tario. Unlike private insurance carriers in the United States, CMPA will proceed to court in defence of the physician even though increased legal fees are incurred, and will not settle a case on the basis of economic expediency.

Is malpractice more common or being more commonly exposed than in the past? The frequency of negligence as opposed to adverse effect has been addressed by several general studies. In a study of California hospital discharges, $4.65 \%$ of cases $(970$ of 20,864$)$ had an iatrogenic injury of which $17 \%$ were categorized as negligence (4). Danzon (5) calculated from these data that legal claims occurred in only one in 10 negligent injuries and that fewer than one in 25 malpractice victims ever received compensation. Another study of 31,429 hospital admissions in New 
TABLE 3

General risk management concepts (15)

1. Understand the basics of tort law

2. Develop a strong doctor-patient relationship

3. Clearly define your role and responsibilities

4. Emphasize the process of informed consent in your practice, and document appropriately

5. Deal with your complications professionally

6. Document well

7. Supervise your employees effectively

8. Understand your liability insurance coverage

York concluded that $1 \%$ of admissions resulted in significant patient injury due to negligence $(6,7)$.

It is apparent from the limited Canadian data that an adverse effect such as an endoscopic perforation is not sufficient for a successful legal claim. However, failure to explain the potential risk of perforation to the patient prior to the procedure or the failure to recognize and treat the complications following a perforation are potentially significant events which could lead to successful legal action. It is also apparent from the American data that it is equally important to inform the patient about the potential risks even with lower risk procedures such as sigmoidoscopy (Figure 5) (6-8). Gerstenberger et al (3) has suggested that the high risk of malpractice claims associated with sigmoidoscopy may relate to a less detailed consent for the presumed lower risk procedures and/or a higher percentage of unskilled operators performing procedures such as sig.

ACKNOWLEDGEMENTS: The author gratefully acknowledges the assistance of Dr R Robson of the Canadian Medical Protective Association and Dr Pat Gerstenberger for the information on the American data. The author is a Career Scientist of the Ministry of Health of Ontario.

\section{REFERENCES}

1. Jacobs WH. The malpractice crisis. Am J Gastroenterol 1985;80:1020.

2. Mills DH. Whither malpractice litigation? West J Med 1988;149:611-5.

3. Gerstenberger PD, Plumeri PA. moidoscopy. It is also apparent from the large American studies in general hospitals that adverse drug reactions are one of the most common causes of iatrogenic injury $(9,10)$. In the context of gastroenterology, it is particularly important to outline the potential side effects of long term corticosteroid therapy and the side effects of cytotoxic agents such as methotrexate and azathioprine. Another potential drug-related issue is sedation and monitoring in the endoscopy room which I have recently reviewed in three Canadian university centres (11). There was only one claim among 610 endoscopy-related incidents in the American database which involved a sedation-related cardiopulmonary arrest (3). Nevertheless, intensive monitoring including pulse oximetry (even though unproven) is becoming increasingly common and practitioners who use sedation during endoscopy will be expected to abide by the 'standard of care' in their area regarding the adequacy of monitoring $(12,13)$. From the American data, it is of interest that the failure to detect colorectal carcinoma is a common cause of successful litigation (3). It may therefore be important to inform the patient that there is a potential for diagnostic error associated with colonoscopy (14). The inadequacy of a colonoscopic evaluation is well known and depends on colonic preparation, anatomy of the colon, identification of landmarks within the colon and persistence of the colonoscopist to examine behind every fold. This is becoming important as the number of patients that proceed di-

Malpractice claims in gastrointestinal endoscopy: Analysis of an insurance industry database. Gastrointest Endosc 1993;39:132-8.

4. Mills DH. California Hospital Association report on the medical insurance feasibility study. San Francisco: Sutter Publications, 1977.

5. Danzon PM. Medical Malpractice: Theory, Evidence and Public Policy. Cambridge: Harvard University Press, 1985.

6. Plumeri PA. The gastroenterologist and the doctrine of informed consent. J Clin Gastroenterol 1983;5:185-7. rectly to endoscopic evaluation without barium contrast studies is increasing. It is also important for the practising gastroenterologist to explain the relevant complications of every procedure to the patient and not to minimize the risk associated with lower risk procedures such as sigmoidoscopy.

The general concepts of a risk management strategy for gastroenterologists have been emphasized in a recent publication by the American Society for Gastrointestinal Endoscopy (Table 3) (15).

It is possible that the number of legal actions against physicians will increase in the future in Canada although the total number of claims has not risen significantly in the past five years (Figure 2). A Canadian physician in 1990 had a one in 35 chance of being named in a legal action in that year. This is approximately fivefold less than the risk in the United States although regional variations in America exist (personal communication). Although malpractice premiums continue to rise for Canadian gastroenterologists (Figure 3), they are still approximately 10 to $20 \%$ of the premiums incurred by American gastroenterologists (16). The observations of large financial awards across the border and other factors, such as the institution of no-fault auto insurance in several provinces, may redirect litigation lawyers away from personal injury cases and towards medical malpractice. Even if medical malpractice never reaches the crisis state that has plagued American medicine, Canadian physicians can learn from observations based on the American experience.

7. Plumeri PA. Informed consent and the gastrointestinal endoscopist. Gastrointest Endosc 1985;31:218-21.

8. Habr-Gama A, Waye JD.

Complications and hazards of gastrointestinal endoscopy. World ] Surg 1989;13:193-201.

9. Hiatt $\mathrm{HH}$, Barnes BA, Brennan TA, et al. A study of medical injury and medical malpractice: An overview. N Engl J Med 1989;321:480-4.

10. Brennan TA, Leape LL, Laird NM, et al. Incidence of adverse events and negligence in hospitalized patients results of the Harvard Medical Practice Study. N Engl J Med 1991;324:370-84. 
11. Golubov J, Adams PC. The university endoscopy unit: The standard of care? Can J Gastroenterol 1990;4:255-8.

12. Williams $C N$, Thomson ABR. Proposed standards for Canadian endoscopy units in the '90s. Can J Gastroenterol 1991;5:47-8.

13. American Society for Gastrointestinal Endoscopy. Monitoring of patients undergoing gastrointestinal endoscopic procedures. Guidelines for clinical applications. Gastrointest Endosc 1991;37:120-1.

14. Plumeri PA, Rogers J. A lawyer's view of colon cancer in the 1980 s. J Clin Gastroenterol 1988;10:229-31.

15. Plumeri PA, Gerstenberger PD, Hughes RW, Miller WN, Smith LE,Taylor DM. Risk Management: An information resource manual.
Manchester, Massachusetts: American Society for Gastrointestinal Endoscopy, 1990.

16. Slora EJ, Gonzalez ML. Medical professional liability claims and premiums, 1985-1989. Socioeconomic characteristics of medical practice 1990/1991. Chicago:

American Medical Association, 1991:15-9. 


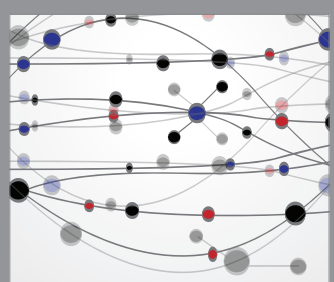

The Scientific World Journal
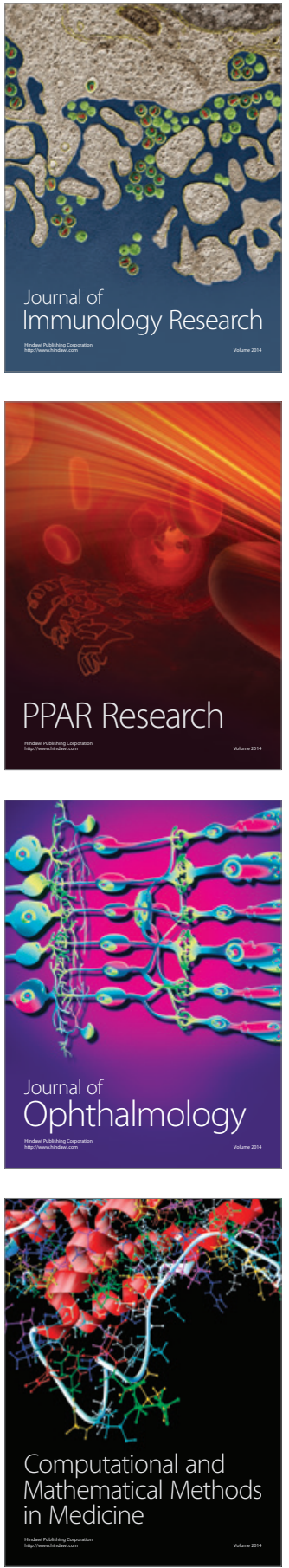

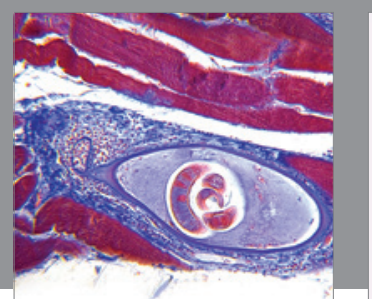

Gastroenterology Research and Practice

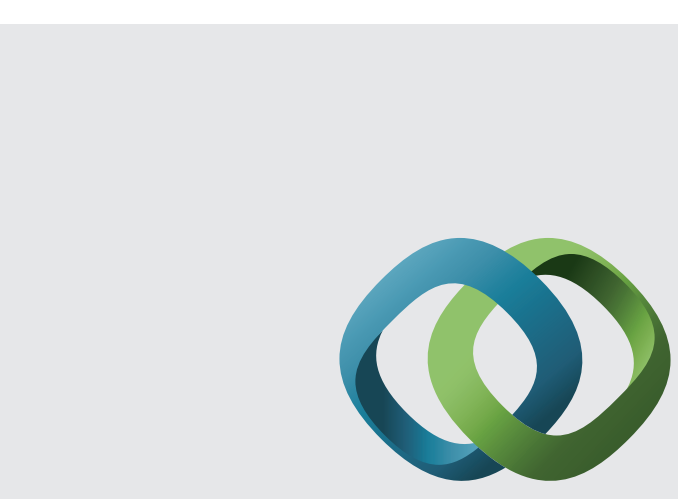

\section{Hindawi}

Submit your manuscripts at

http://www.hindawi.com
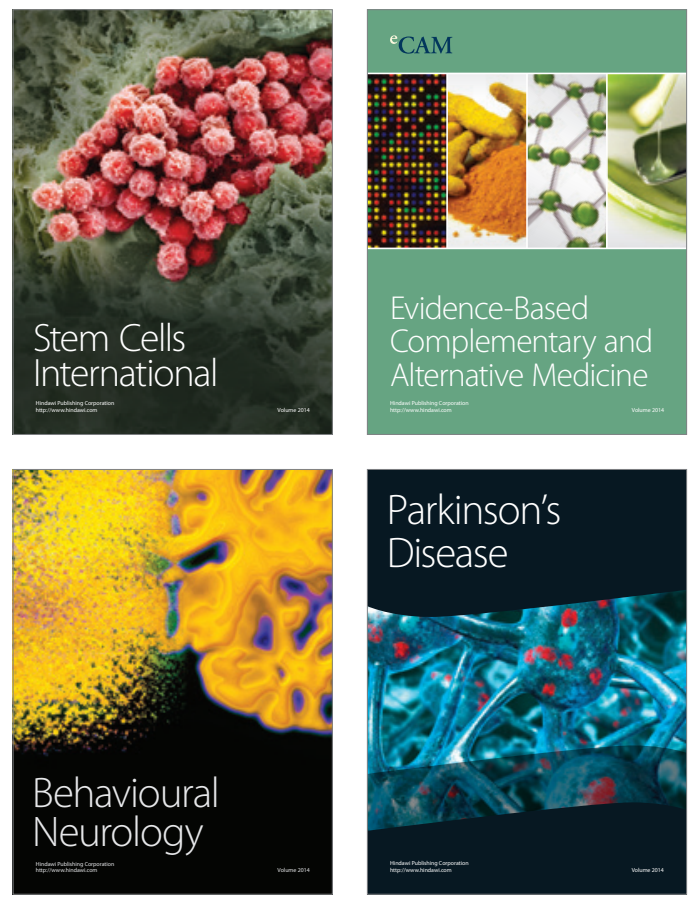
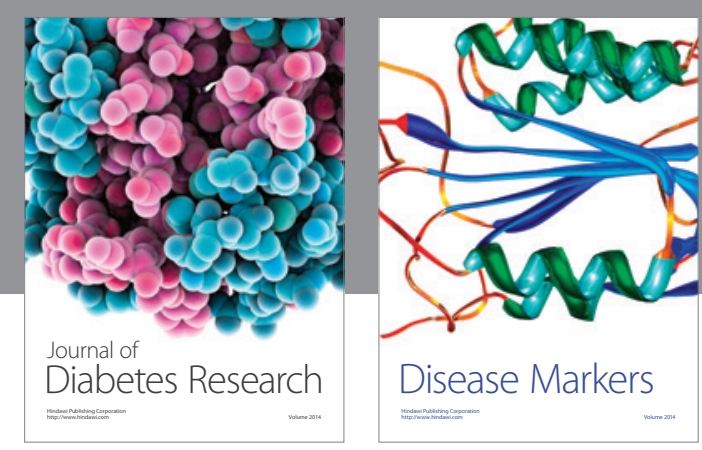

Disease Markers
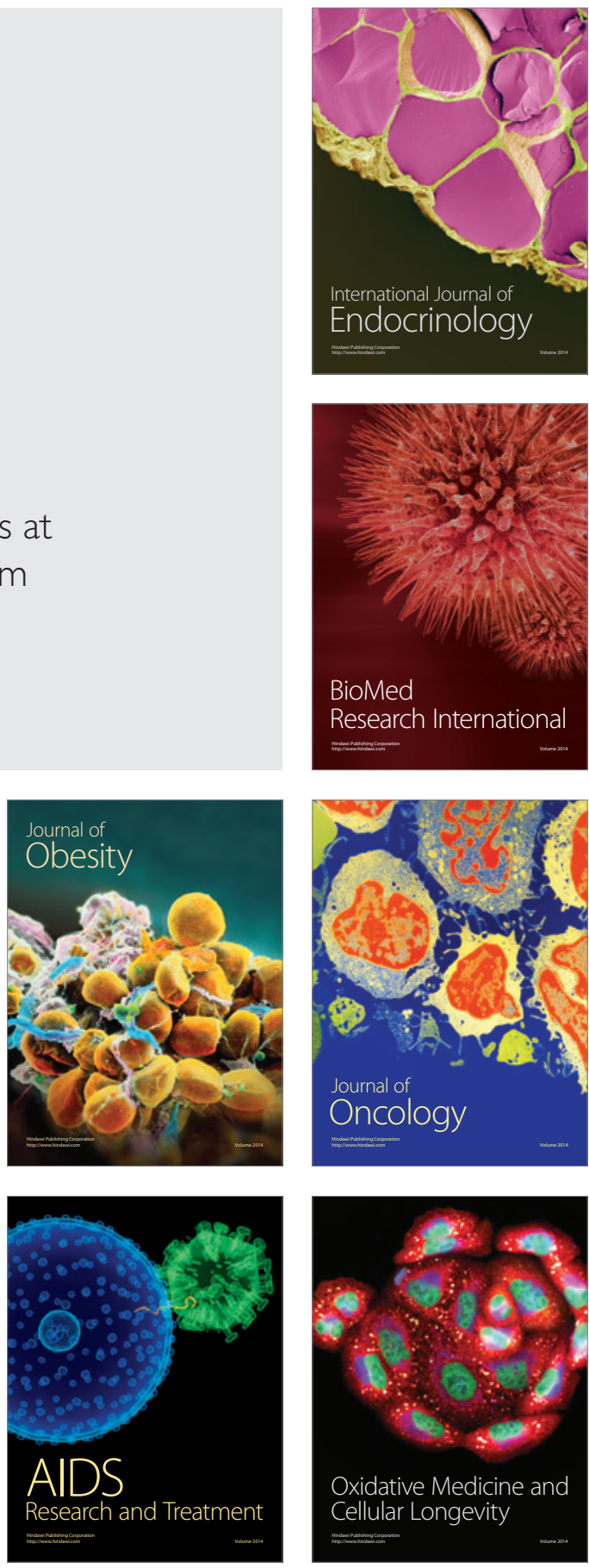